\title{
Psychiatry beyond the current paradigm ${ }^{\dagger}$
}

Pat Bracken, Philip Thomas, Sami Timimi, Eia Asen, Graham Behr, Carl Beuster, Seth Bhunnoo, Ivor Browne, Navjyoat Chhina, Duncan Double, Simon Downer, Chris Evans, Suman Fernando, Malcolm R. Garland, William Hopkins, Rhodri Huws, Bob Johnson, Brian Martindale, Hugh Middleton, Daniel Moldavsky, Joanna Moncrieff, Simon Mullins, Julia Nelki, Matteo Pizzo, James Rodger, Marcellino Smyth, Derek Summerfield, Jeremy Wallace and David Yeomans

\begin{abstract}
Summary
A series of editorials in this Journal have argued that psychiatry is in the midst of a crisis. The various solutions proposed would all involve a strengthening of psychiatry's identity as essentially 'applied neuroscience'. Although not discounting the importance of the brain sciences and psychopharmacology, we argue that psychiatry needs to move beyond the dominance of the current, technological
\end{abstract}

paradigm. This would be more in keeping with the evidence about how positive outcomes are achieved and could also serve to foster more meaningful collaboration with the growing service user movement.

\section{Declaration of interest}

None.
What makes a good psychiatrist? What particular skills are needed to practice a 'medicine of the mind'? Although it is impossible to answer such questions fully we believe that there is mounting evidence that good practice in psychiatry primarily involves engagement with the non-technical dimensions of our work such as relationships, meanings and values. Psychiatry has thus far been guided by a technological paradigm that, although not ignoring these aspects of our work, has kept them as secondary concerns. The dominance of this paradigm can be seen in the importance we have attached to classification systems, causal models of understanding mental distress and the framing of psychiatric care as a series of discrete interventions that can be analysed and measured independent of context.

In recent years this Journal has published a series of editorials arguing that the profession should adopt an even more technological and biomedical identity, and that psychiatrists should focus on their mastery of technology to allow progress in the development of brain research, genetics, pharmacology and neuroradiology. ${ }^{2-4}$ These resonate with calls in North America for psychiatry to become simply a 'clinical neuroscience. ${ }^{5}$ However, the promise of therapeutic gains from the brain sciences always seems to be for the future, leading some to interrogate their contribution to advances in our field. ${ }^{6}$ Indeed, neuroscientists themselves have become more cautious about the value of reductionist approaches to understanding the nature of human thought, emotion and behaviour. ${ }^{7,8}$ Furthermore, there is ample evidence that anti-stigma campaigns based on biogenetic models of serious mental illness have been counterproductive. ${ }^{9}$

The increasing focus on neuroscience has meant that other important developments in the provision of care and support for people with mental health problems over the course of the past century have been neglected. Historically, these have been driven mostly by non-technical changes that have fostered empowerment and social inclusion. ${ }^{10}$ It is generally agreed that the closure of the large Victorian asylums improved patients' quality of life. But this was mainly the result of economic imperatives combined with a growing realisation of the negative effects of institutionalisation, rather than, as frequently suggested, a consequence of the introduction of new drugs. ${ }^{11,12}$ Other positive developments have resulted from the establishment of multidisciplinary, communitybased care and the rise of the service user movement and

†See editorial, pp. 421-422, this issue. voluntary sector supports. Many psychiatrists have worked hard to promote these developments but the increasing focus on technical and biomedical aspects of care have served to sideline such efforts.

\section{The technological paradigm}

Since its origins in the asylums of the 19th century, ${ }^{13}$ psychiatry has faced a fundamental question: can a medicine of the mind work with the same epistemology as a medicine of the tissues? Through the 19th and 20th centuries, psychiatry held fast to the idea that mental health problems are best understood through a biomedical idiom; that problems with feelings, thoughts, behaviours and relationships can be fully grasped with the same sort of scientific tools that we use to investigate problems with our livers and lungs. In more recent decades, models of cognitive psychology, such as 'information processing', have been developed that work with the same technical idiom. ${ }^{14}$ The 'technological paradigm' that now guides psychiatry incorporates these perspectives, works with a positivist orientation ${ }^{15}$ and involves the following assumptions.

(a) Mental health problems arise from faulty mechanisms or processes of some sort, involving abnormal physiological or psychological events occurring within the individual.

(b) These mechanisms or processes can be modelled in causal terms. They are not context-dependent.

(c) Technological interventions are instrumental and can be designed and studied independently of relationships and values.

In the technological paradigm, mental health problems can be mapped and categorised with the same causal logic used in the rest of medicine, and our interventions can be understood as a series of discrete treatments targeted at specific syndromes or symptoms. Relationships, meanings, values, cultural beliefs and practices are not ignored but become secondary in importance. This order of priorities is reflected in our understanding of the training needs of future psychiatrists, what gets published in journals, what topics are selected for analysis at conferences, the types of research that are promoted and how we conceptualise our relationship with the service user movement.

We suggest that this paradigm has not served psychiatry well. Ignoring fundamental epistemological issues at the heart of our 
models does not make them go away. Moreover, it does not yield results that are consistent with the demands of evidence-based medicine. Many inside and outside the profession are asking searching questions that challenge current theory and practice. For example, Marcia Angell, former editor of the New England Journal of Medicine, launched a serious attack on the orientation and practice of modern psychiatry in a series of book reviews last year. ${ }^{16,17}$ The technological paradigm underscores a trend towards the medicalisation of everyday life, which, in turn, is associated with expanding markets for psychotropic agents. This has drawn widespread criticism, including from the chair of the DSM-IV taskforce. ${ }^{18}$ This process has also led to the corruption of sections of academic psychiatry through its entanglement with the pharmaceutical industry, damaging the profession's credibility in the process. ${ }^{19}$

Psychiatry now faces two challenges it cannot ignore. First, a growing body of empirical evidence points to the primary importance of the non-technical aspects of mental healthcare. If we are genuine about promoting 'evidenced-based' practice, we will have to take this seriously. Second, real collaboration with the service user movement can only happen when psychiatry is ready to move beyond the primacy of the technical paradigm. In contrast to the thrust of recent editorials, we argue that substantive progress in our field will not come from neuroscience and pharmaceuticals (important as these might be) but from a fundamental re-examination of what mental healthcare is all about and a rethinking of how genuine knowledge and expertise can be developed in the field of mental health.

\section{Empirical evidence that challenges the current paradigm}

Many of our patients benefit from psychiatric care and report improvements with drug treatments and different forms of psychotherapy. This is not in doubt. But how do such improvements come about? We will look at the evidence relating to therapeutic change in depression and allied conditions first. We will then look at the evidence for 'serious mental illness' (a term that usually covers syndromes such as 'schizophrenia' and 'bipolar disorder').

\section{Therapeutic change in depression and allied conditions}

There is strong evidence that improvement in depression comes mainly from non-technical aspects of interventions. Recent meta-analyses of drug treatments for depression demonstrate that drug-placebo differences are minimal. ${ }^{20-23}$ Even in subgroups of individuals who are more severely depressed, where differences have been reported as being clinically significant, they are still small in absolute terms and may be simply the result of decreased responsiveness to placebo. ${ }^{24}$ The placebo effect is a complex phenomenon involving conscious and unconscious experiences. ${ }^{25,26}$ Among other things, it involves the mobilisation of a sense of hope and meaning ${ }^{27}$ and it would appear that this is the principal way in which these drugs work. The psychoactive effects of antidepressants, such as the sedative effects of tricyclics and the emotional disengagement produced by selective serotonin reuptake inhibitors, are also likely to be relevant to their performance in clinical trials, and may or may not be experienced as helpful by some individuals. Overall, available evidence does not support the idea that antidepressants work by correcting a pre-existing 'chemical imbalance. ${ }^{28}$

Two recent reviews of comparisons of real with 'sham' electroconvulsive therapy (ECT) also highlight the importance of non-technical aspects of this treatment. Rasmussen ${ }^{29}$ concludes that 'substantial proportions of what seemed to be severely ill patients responded to sham treatment quite robustly'. None of the studies reviewed by Read \& Bentall ${ }^{30}$ found significant differences between real and sham ECT after the treatment period. The Northwick Park study, ${ }^{31}$ regarded by many as the best designed controlled study of ECT, ${ }^{32}$ is often quoted as having found evidence to support the use of ECT. However, there was no significant difference, over a 4 -week treatment period, between real and sham ECT on ratings by patients or nurses. The single positive difference (for a 'deluded' group, and perceived by psychiatrists alone) had disappeared 1 month after the end of treatment. By 6 months, there was actually a two-point difference in scores on the Hamilton Rating Scale for Depression in favour of the sham treatment. It is unlikely that the trial, if designed and executed now to current trial guidelines, could have been reported as supporting the use of ECT and it is notable that the researchers, even then, concluded that: 'many depressive illnesses although severe may have a favourable outcome with intensive nursing and medical care even if physical treatments are not given., ${ }^{31}$

Similar conclusions emerge from the literature on psychotherapy. Cognitive-behavioural therapy (CBT) is the form of psychotherapy most widely promoted today. Its proponents argue that it works by rectifying faulty cognitions that are believed to cause depression. ${ }^{33}$ However, several studies have shown that most of the specific features of CBT can be dispensed with without adversely affecting outcomes. ${ }^{34}$ A comprehensive review of studies of the different components of CBT concluded that there is '. . . little evidence that specific cognitive interventions significantly increase the effectiveness of the therapy'. ${ }^{35}$

The evidence that non-specific factors, as opposed to specific techniques, account for nearly all the change in therapy is overwhelming. In their review of the evidence on the effectiveness of psychotherapy, Budd \& Hughes write 'no clear pattern of superiority for any one treatment has emerged'. ${ }^{36}$ Cooper provides an up-to-date and comprehensive examination of the empirical research on psychotherapy in general. ${ }^{37}$ What emerges from the evidence is that non-specific factors (client variables, extratherapeutic events, relationship variables and expectancy and placebo effects) account for about $85 \%$ of the variance in therapeutic outcomes across the psychotherapy field. In particular, the relationship between therapeutic alliance and outcome seems remarkably robust across treatment modalities and clinical presentations. $^{38}$ The lack of markedly enhanced outcomes from the use of specific techniques is not limited to research settings. For example, in a review of over 5000 cases treated in a variety of National Health Service settings in the UK, no significant variance in outcome could be attributed to the specific psychotherapeutic model used, with non-specific factors such as the therapeutic relationship accounting for most of the variance in outcomes. ${ }^{39}$ This has caused some difficulty in developing national guidelines. Although the National Institute for Health and Clinical Excellence (NICE) Quick Reference Guide ${ }^{40}$ provides clear and definitive recommendations as to what therapies are recommended in states of depression, an exploration of the full guideline (Clinical Guideline 90$)^{22}$ reveals that, in reality, the evidence for the superiority of a particular approach is far from clear-cut.

\section{Recovery from serious mental illness}

The move away from a technological paradigm resonates strongly with key insights from the 'recovery approach' to mental healthcare that has become increasingly influential. ${ }^{10}$ There is a growing appreciation that personally meaningful recovery from 
serious mental disorder is not necessarily related to the specific treatments that are prescribed. ${ }^{41}$ Research has pointed to the importance of the therapeutic alliance in determining outcomes. ${ }^{42}$ Others have pointed to the importance of self-esteem and an 'internal locus of control. ${ }^{43}$ It seems that creating a therapeutic context that promotes empowerment and connectedness and that helps rebuild a positive self-identity is of great significance. ${ }^{44,45}$

The concept of recovery is still in development. ${ }^{46}$ Evidence from non-Western settings ${ }^{47}$ and communities ${ }^{48}$ reveals that people recover from serious mental illness through many pathways, pointing to the crucial importance of respecting diversity in mental health work, both theoretically and therapeutically. ${ }^{49}$

At the same time, it is increasingly recognised that specific technical interventions, such as drugs, have a limited impact on the overall burden of serious mental illness. ${ }^{50} \mathrm{~A}$ meta-analysis of randomised controlled trials investigating the effectiveness of first- and second-generation antipsychotic drugs found that, at best, the improvements seen in two commonly used rating scales (the Brief Psychiatric Rating Scale and the Positive and Negative Syndrome Scale) were 'disappointingly limited.51 Although the authors' caution against the conclusion that antipsychotics have 'negligible effects in clinical practice', given their findings, and those of other groups, ${ }^{52}$ such a conclusion does not seem unreasonable. Over-reliance on psychopharmacology as the primary response to serious mental illness created the conditions for a blindness towards the serious adverse effects of some psychiatric drugs, and for a shameful collusion with the pharmaceutical industry's marketing campaign that sold the illusion of major innovations in antipsychotic drugs. The claimed therapeutic advances were, in fact, 'spurious.' ${ }^{53}$ As Kendall put it recently 'the story of the atypicals and the SGAs [second-generation antipsychotics] is not the story of clinical discovery and progress; it is the story of fabricated classes, money and marketing. ${ }^{54}$ These drugs are associated with increased cardiovascular risk. ${ }^{55}$ Such iatrogenic effects have been cited as one of the reasons for the significantly decreased life expectancy of people with mental illness. ${ }^{56}$

The balance of evidence does not support the idea that mental health problems are best grasped through a technical idiom or that good mental health work can be characterised as a series of discrete interventions. This is not to say that medical knowledge and expertise are not relevant, and even vital, in the field of mental health. However, the problems we grapple with cry out for a more nuanced form of medical understanding and practice. As Kirmayer \& Gold put it recently 'Defining psychiatry as applied neuroscience valorizes the brain but urges on us a discipline that is both mindless and uncultured. ${ }^{57}$ We need to develop an approach to mental health problems that is genuinely sensitive to the complex interplay of forces (biological, psychological, social and cultural) that underlie them and that can be used therapeutically. The evidence is becoming clear that to improve outcomes for our patients, we must focus more on contexts, relationships and the creation of services where the promotion of dignity, respect, meaning and engagement are prioritised. ${ }^{10}$ We must become more comfortable with cultural diversity, user empowerment and the importance of peer support. ${ }^{58}$

\section{Collaboration with the service user movement}

Although patients with mental illness were collectively pursuing their goals as far back as the 17 th century, ${ }^{59}$ it was not until the 1980s that effective user organisations emerged. Since then the rise of the movement has been rapid. In the UK alone, it is now estimated that there are at least 300 groups with an approximate membership of $9000 .^{60}$ The service user movement is now worldwide, with organisations set up by service users consulted by national governments, the World Health Organization, the United Nations and the World Psychiatric Association. ${ }^{61}$

Although some service users are happy to define themselves and their problems through a biomedical framework, many others are not. Such groups and individuals hold a variety of views, but are generally united by a rejection of the technological framework and the way it defines their problems through an expert vocabulary and logic. A good example is the Hearing Voices Network (HVN). This emerged in the Netherlands in the late 1980s, after it was initiated by the psychiatrist Marius Romme. ${ }^{62}$ It has spread across Europe and America largely through the efforts of people who hear voices. The HVN is not only a peer support organisation but also offers a different way of understanding and responding to voice hearing. Other organisations, such as Mind Freedom International and the Icarus Project not only offer peer support, but also challenge the dominant psychopathological framework. Thus, large sections of the service user movement seek to reframe experiences of mental illness, distress and alienation by turning them into human, rather than technical, challenges. $^{63}$

There is also evidence that many patients who are not active in the service user movement find psychiatric interventions problematic and sometimes harmful. In their study of users' views of services, Rogers et $a l^{64}$ found that many service users did not really value the technical expertise of the professionals. Instead, they were more concerned with the human aspects of their encounters such as being listened to, taken seriously, and treated with dignity, kindness and respect.

\section{Conclusion}

Psychiatry is not neurology; it is not a medicine of the brain. Although mental health problems undoubtedly have a biological dimension, in their very nature they reach beyond the brain to involve social, cultural and psychological dimensions. These cannot always be grasped through the epistemology of biomedicine. The mental life of humans is discursive in nature. As Harré \& Gillet put it 'We must learn to see the mind as the meeting point of a range of structuring influences whose nature can only be painted on a broader canvas than that provided by the study of individual organisms. ${ }^{14}$ Reductionist models fail to grasp what is most important in terms of recovery. The evidence base is telling us that we need a radical shift in our understanding of what is at the heart (and perhaps soul) of mental health practice. If we are to operate in an evidence-based manner, and work collaboratively with all sections of the service user movement, we need a psychiatry that is intellectually and ethically adequate to deal with the sort of problems that present to it. As well as the addition of more social science and humanities to the curriculum of our trainees we need to develop a different sensibility towards mental illness itself and a different understanding of our role as doctors. ${ }^{65}$ We are not seeking to replace one paradigm with another. A post-technological psychiatry will not abandon the tools of empirical science or reject medical and psychotherapeutic techniques but will start to position the ethical and hermeneutic aspects of our work as primary, thereby highlighting the importance of examining values, relationships, politics and the ethical basis of care and caring.

Such a shift will have major implications for our research priorities, the skills we teach our trainees, the sort of services we seek to develop and the role we play in managing risk. This represents a substantial, but exciting, challenge to our profession 
to recognise what it does best. We will always need to use our knowledge of the brain and the body to identify organic causes of mental disturbance. We will also need knowledge of psychopharmacology to provide relief from certain forms of distress. But good psychiatry involves active engagement with the complex nature of mental health problems, a healthy scepticism for biological reductionism, tolerance for the tangled nature of relationships and meanings and the ability to negotiate these issues in a way that empowers service users and their carers. Just as operating skills are at the heart of good surgical practice, skills in working with multiple layers of knowledge and many systems of meaning are at the heart of our work. We will never have a biomedical science that is similar to hepatology or respiratory medicine, not because we are bad doctors, but because the issues we deal with are of a different nature.

Understanding the unique contribution psychiatry makes to healthcare can only increase our relevance to the rest of medicine. All forms of suffering involve layers of personal history, embedded in a nexus of meaningful relationships that are, in turn, embedded in cultural and political systems. Kleinman \& van der Geest have rightly critiqued the way in which medicine in general has come to see 'caregiving' in purely technical terms. ${ }^{66}$ Similarly, Heath has argued for the importance of relationships and narrative understanding in general practice. ${ }^{67}$ Psychiatry has the potential to offer leadership in this area. Retreating to an even more biomedical identity will not only sell our patients short, but risks leading the profession down a single narrow alley, when what is needed is openness to alternative routes.

Pat Bracken, MD, MRCPsych, PhD, Centre for Mental Health Care and Recovery, Bantry General Hospital, Bantry, Ireland; Philip Thomas, MPhil, FRCPsych, MD, University of Bradford, Bradford, UK; Sami Timimi, FRCPsych, Lincolnshire Partnership NHS Foundation Trust Child and Family Services Horizons Centre, Lincoln, UK; Eia Asen, MD, FRCPsych, Marlborough Family Service, Central and North West London Foundation NHS Trust, London, UK; Graham Behr, MRCPsych, Central and North West London Foundation NHS Trust, London, UK' Carl Beuster, MRCPSych, Southern Health NHS Foundation Trust, UK; Seth Bhunnoo, MA, MPhil, MRCPsych, Southern Health NHS Foundation Trust, UK; Seth Bhunnoo, MA, MPhil, MRCPSych,
The Halliwick Centre, Haringey Complex Care Team, St Ann's Hospital, Barnet, Enfield and Haringey Mental Health NHS Trust, London, UK; Ivor Browne, FRCPI, FRCPsych, MSC (Harv), DPM, University College Dublin, Dublin, Ireland; Navjyoat Chhina, MA (Oxon), MSC, MRCPsych, Early Intervention Team, Cumbria Partnership NHS Foundation Trust, Penrith, UK; Duncan Double, MA, MRCPsych, Norfolk \& Suffolk NHS Foundation Trust, Norwich, UK; simon Downer, MRCPsych, Severn Deanery School of Psychiatry, Bristol, UK; Chris Evans, MRCPsych, MSc, MinstGA School of Psychiatry, Bristol, UK; Chris Evans, MRCPSych, MSC, MinstGA,
Nottinghamshire Healthcare NHS Trust, Nottingham, UK; Suman Fernando Nottinghamshire Healthcare NHS Trust, Nottingham, UK; Suman Fernando,
FRCPsych, Faculty of Social Sciences \& Humanities, London Metropolitan University, London, UK; Malcolm R. Garland, MD, MRCPI, MRCPsych, St Ita's Hospital, Portrane, Ireland; William Hopkins, FRCpsych, Barnet Enfield and Haringey Mental Health NHS Trust, London, UK; Rhodri Huws, FRCPsych, Eastglade Community Health Centre, Sheffield, UK; Bob Johnson, MRCPsych, MRCGP, MA, PhD, Rivington House Clinic, UK; Brian Martindale, FRCP FRCPsych, Northumberland, Tyne and Wear NHS Foundation Trust, Newcastle upon Tyne, UK; Hugh Middleton, MD, MRCP, Foundation Trust, Newcastle upon Tyne, UK; Hugh Middleton, MD, MRCP,
FRCPsych, School of Sociology and Social Policy, University of Nottingham and Nottinghamshire Healthcare NHS Trust, Nottingham, UK; Daniel Moldavsky, Specialist Associate RCPsych, Nottinghamshire Healthcare NHS Trust, Nottingham, UK; Joanna Moncrieff, MRCPsych, Department of Mental Health Sciences, University College London, London, UK; simon Mullins, MRCPych, Sheffield Health and Socia Care NHS Foundation Trust, Sheffield, UK; Julia Nelki, FRCPsych, Chester Eating Disorders Service, Chester, UK; Matteo Pizzo, PGDip, MRCPsych, St Ann's Hospital London, UK; James Rodger, MRCPsych, South Devon CAMHS, Devon Partnership NHS Trust, Exeter, UK; Marcellino Smyth, MRCPsych, MMedSci, MD, Centre for Mental Health Care and Recovery, Bantry, Ireland; Derek Summerfield, MRCPsych, CASCAID, Maudsley Hospital, London, UK; Jeremy Wallace, MSC, MRCPsych, HUS (Helsinki University Sairaala) Peijas, Vantaa, Finland; David Yeomans, MMedSC MRCPsych, Leeds \& York Partnership NHS Foundation Trust, Leeds, UK

Correspondence: Pat Bracken, MD, MRCPsych, PhD, Centre for Mental Health Care and Recovery, Bantry General Hospital, Bantry, Co Cork, Ireland. Email: Pat.Bracken@hse.ie

First received 8 Mar 2012, final revision 10 Jul 2012, accepted 27 Sep 2012

\section{References}

1 Radden J. Thinking about the repair manual: technique and technology in psychiatry. In Philosophical Perspectives on Technology and Psychiatry (ed J Philips): 263-77. Oxford University Press, 2008.
2 Craddock N, Antebi D, Attenburrow M-J, Bailey A, Carson A, Cowen P, et al. Wake-up call for British psychiatry. Br J Psychiatry 2008; 193: 6-9.

3 Bullmore $E$, Fletcher $P$, Jones $P B$. Why psychiatry can't afford to be neurophobic. Br J Psychiatry 2009; 194: 293-5.

4 Oyebode F, Humphreys M. The future of psychiatry. Br J Psychiatry 2011; 199: 439-40.

5 Insel TR, Quiron R. Psychiatry as a clinical neuroscience discipline. JAMA 2005; 294: 2221-4.

6 Kingdon D, Young AH. Research into putative biological mechanisms of mental disorders has been of no value to clinical psychiatry. Br J Psychiatry 2007; 191: 285-90.

7 Rose S. The need for a critical neuroscience: from neuroideology to neurotechnology. In Critical Neuroscience: A Handbook of the Social and Cultural Contexts of Neuroscience (eds S Choudhury, J Slaby): 53-66. Wiley-Blackwell, 2012

8 Vul E, Harris C, Winkelmann P, Pashler H. Puzzlingly high correlations in fMRI studies of emotion, personality, and social cognition. Perspect Psychol Sci 2009; 4: 319-24.

9 Angermeyer MC, Holzinger A, Carta MG, Schomerus G. Biogenetic explanations and public acceptance of mental illness: systematic review of population studies. Br J Psychiatry 2011; 199: 367-72.

10 Slade M. Personal Recovery and Mental IIIness. Cambridge University Press, 2009.

11 Gronfein W. Psychotropic drugs and the origins of deinstitutionalization. SoC Probl 32: 437-54.

12 Aviram U, Syme SI, Cohen JB. The effects of policies and programs on reduction of mental hospitalization. Soc Sci Med 1976; 10: 571-7.

13 Porter R. A Social History of Madness: Stories of the Insane. Weidenfeld and Nicolson, 1987.

14 Harré R, Gillett G. The Discursive Mind. Sage, 1994

15 Ingleby D. Critical Psychiatry: The Politics of Mental Health. Penguin, 1980.

16 Angell M. The illusions of psychiatry. New York Rev Books 2011, 14 July (http://www.nybooks.com/articles/archives/2011/jul/14/ illusions-of-psychiatry/? pagination = false).

17 Angell M. The epidemic of mental illness: why? New York Rev Books 2011 23 June (http://www.nybooks.com/articles/archives/2011/jun/23/epidemicmental-illness-why/).

18 Frances A. The first draft of DSM-V: if accepted, will fan the flames of false positive diagnoses. BMJ 2010; 340: c1168.

19 Carey B, Harris G. Psychiatric group faces scrutiny over drug industry ties. New York Times 2008; 12 July (http://www.nytimes.com/2008/07/12/ washington/12psych.html? pagewanted = all).

20 Andrews G. Placebo response in depression: bane of research, boon to therapy. Br J Psychiatry 2001; 178: 192-4.

21 Kirsch I, Sapirstein G. Listening to prozac but hearing placebo: a metaanalysis of antidepressant medication 1998. Prev Treat 1998; 1: 0002a.

22 National Institute for Health and Clinical Excellence (NICE) (2009). Depression: The Treatment and Management of Depression in Adults. NICE Clinical Guideline CG90. London: NICE (http://guidance.nice.org.uk/CG90).

23 Fournier JC, DeRubeis RJ, Hollon SD, Dimidjian S, Amsterdam JD, Shelton RC, et al. Antidepressant drug effects and depression severity: a patient-level meta-analysis. JAMA 2010; 303: 47-53.

24 Kirsch I, Deacon BJ, Huedo-Medina TB, Scoboria A, Moore TJ, Johnson BT. Initial severity and antidepressant benefits: a meta-analysis of data submitted to the Food and Drug Administration. PLOS Med 2008; 5: e45.

25 Thompson JJ, Ritenbaugh C, Nichter M. Reconsidering the placebo response from a broad anthropological perspective. Cult Med Psychiatry 2009; 33 112-52.

26 McQueen D, St John Smith P. Placebo effects: a new paradigm and relevance to psychiatry. Int Psychiatry 2012; 9: 1-3.

27 Moerman D. Meaning, Medicine and the 'Placebo Effect'. Cambridge University Press, 2002

28 Moncrieff J. The Myth of the Chemical Cure: A Critique of Psychiatric Drug Treatment. Palgrave Macmillan, 2008

29 Rasmussen K. Sham electroconvulsive therapy studies in depressive illness: a review of the literature and consideration of the placebo phenomenon in electroconvulsive therapy practice. J ECT 2009; 25: 54-9.

30 Read J, Bentall R. The effectiveness of electroconvulsive therapy: a literature review. Epidemiol Psichiatr Soc 2010; 19: 333-47.

31 Johnstone EC, Deakin JFW, Lawler P, Frith CD, Stevens M, McPherson K. The Northwick Park electroconvulsive therapy trial. Lancet 1980; 2: 1317-20.

32 Kendell R. The present state of electroconvulsive therapy. Br J Psychiatry 1981; 139: 265-83. 
33 Beck AT. Cognitive therapy: past, present, and future. J Consult Clin Psychol 1993; 61: 194-8.

34 Jacobson NS, Dobson KS, Truax PA, Addis M, Koerner K, Gollan JK, et al. A component analysis of cognitive-behavioural treatment for depression. $J$ Consult Clin Psychol 1996; 64: 295-304.

35 Longmore RJ, Worrell M. Do we need to challenge thoughts in cognitive behaviour therapy? Clin Psychol Rev 2007; 27: 173-87.

36 Budd R, Hughes I. The dodo bird verdict - controversial, inevitable and important: a commentary on 30 years of meta-analyses. Clin Psychol Psychother 2009; 16: 510-22.

37 Cooper M. Essential Research Findings in Counselling and Psychotherapy: The Facts are Friendly. Sage, 2008.

38 Castonguay LG, Beutler LE. Common and unique principles of therapeutic change: what do we know and what do we need to know? In Principles of Therapeutic Change that Work (eds LG Castonguay, LE Beutler): 353-69. Oxford University Press, 2006.

39 Stiles WB, Barkham M, Mellor-Car J. Effectiveness of cognitive-behavioural, person-centred, and psychodynamic therapies in UK primary-care routine practice: replication in a larger sample. Psychol Med 2008; 38: 677-88.

40 National Institute for Health and Clinical Excellence (2009) Quick Reference Guide. Depression: Treatment and Management of Depression in Adults, including Adults with a Chronic Physical Health Problem. London: NICE (http://www.nice.org.uk/nicemedia/live/12329/45890/45890.pdf).

41 Davidson L. Living Outside Mental Illness: Qualitative Studies of Recovery in Schizophrenia. New York University Press, 2003.

42 Frank AF, Gunderson JG. The role of the therapeutic alliance in the treatment of schizophrenia. Arch Gen Psychiatry 1990; 47: 228-36.

43 Harrow $\mathrm{M}$, Jobe $\mathrm{TH}$. Factors involved in outcome and recovery in schizophrenia patients not on antipsychotic medications: a 15-year multifollow-up study. J Nerv Ment Dis 2007; 195: 406-14.

44 Mancini MA, Hardiman ER, Lawson HA. Making sense of it all: consumer providers' theories about factors facilitating and impeding recovery from psychiatric disabilities. Psychiatr Rehabil J 2005; 29: 48-55.

45 Tew J, Ramon S, Slade M, Bird V, Melton J, Le Boutillier C. Social factors and recovery from mental health difficulties: a review of the evidence. $\mathrm{Br} J \mathrm{SOC}$ Work 2012; 42: 443-60.

46 Leamy M, Bird V, Le Boutillier C, Williams J, Slade M. Conceptual framework for personal recovery in mental health: systematic review and narrative synthesis. Br J Psychiatry 2011; 199: 445-52.

47 Raguram R, Venkateswaran A, Ramakrishna J, Weiss MG. Traditional community resources for mental health: a report of temple healing from India. BMJ 2002; 325: 38-40.

48 Seebohm P, Henderson P, Munn-Giddings C, Thomas P, Yasmeen S. Together We Will Change: Community Development, Mental Health and Diversity. Sainsbury Centre for Mental Health, 2005.
49 Halliburton M. Finding a fit: psychiatric pluralism in South India and its implications for WHO studies of mental disorder. Transcult Psychiatry 2004; 41: 80-98.

50 Warner R. How much of the burden of schizophrenia is alleviated by treatment? Br J Psychiatry 2003; 183: 375-6.

51 Lepping P, Sambhi RS, Whittington R, Lane S, Poole R. Clinical relevance of findings in trials of antipsychotics: systematic review. Br J Psychiatry 2011; 198: $341-5$

52 Bola JR, Kao DT, Soydan H. Antipsychotic medication for early-episode schizophrenia. Schizophr Bull 2012; 38: 23-5.

53 Tyrer $\mathrm{P}$, Kendall $\mathrm{T}$. The spurious advance of antipsychotic drug therapy. Lancet 2009; 373: 4-5.

54 Kendall T. The rise and fall of the atypical antipsychotics. Br J Psychiatry 2011; 199: 266-8.

55 Foley DL, Morley KI. Systematic review of early cardiometabolic outcomes of the first treated episode of psychosis. Arch Gen Psychiatry 2011; 68: 609-16.

56 Thornicroft G. Physical health disparities and mental illness: the scandal of premature mortality. Br J Psychiatry 2011; 199: 441-2.

57 Kirmayer $\sqcup$, Gold I. Re-socializing psychiatry: critical neuroscience and the limits of reductionism. In Critical Neuroscience: A Handbook of the Social and Cultural Contexts of Neuroscience (eds S Choudhury, J Slaby): 307-30. Wiley-Blackwell, 2012.

58 Warner R. Does the scientific evidence support the recovery model? Psychiatrist 2010; 34: 3-5.

59 Campbell P. The service user/survivor movement. In Mental Health Still Matters (eds J Reynolds, R Muston, T Heller, J Leach, M McCormick, J Wallcraft and M Walsh): 46-52. Open University/Palgrave Macmillan, 2009.

60 Wallcraft J, Read J, Sweeney A. On Our Own Terms: Users and Survivors of Mental Health Services Working Together for Support and Change. Sainsbury Centre for Mental Health, 2003.

61 MindFreedom. Global Campaign News. MindFreedom, no date (http:// www.mindfreedom.org/campaign/global).

62 Romme M, Escher S. Accepting Voices. MIND, 1993.

63 Stastny P, Lehmann P. Alternatives Beyond Psychiatry. Peter Lehmann Publishing, 2007.

64 Rogers A, Pilgrim D, Lacey R. Experiencing Psychiatry: Users' Views of Services. MacMillan, 1993.

65 Roberts G, Wolfson P. The rediscovery of recovery: open to all. Adv Psychiatr Treat 2004; 10: 37-48.

66 Kleinman A, van der Geest S. 'Care' in health care. Remaking the moral world of medicine. Med Anthropol 2009; 21: 159-68.

67 Heath I. Divided we fall. The 2011 Harveian oration delivered to the Royal College of Physicians on October 18th 2011. Clin Med 2011; 11: 576-86. 